Short Communication

\title{
Borrelia burgdorferi sensu lato in humans in a rural area of Paraná State, Brazil
}

\author{
Daniela Dib Gonçalves ${ }^{1,2}$, Rodrigo Assunção Moura ${ }^{2}$, Mônica Nunes ${ }^{3}$, \\ Teresa Carreira $^{3}$, Odilon Vidotto ${ }^{4}$, Julio Cesar Freitas ${ }^{4}$, Maria Luísa Vieira ${ }^{3}$ \\ ${ }^{1}$ Programa de Pós-gradução em Ciência Animal, Universidade Estadual de Londrina, \\ Londrina, PR, Brazil. \\ ${ }^{2}$ Medicina Veterinária Preventiva, Universidade Paranaense, Umuarama, PR, Brazil. \\ ${ }^{3}$ Leptospirosis and Lyme Borreliosis Group, Medical Microbiology Unit, \\ Institute of Hygiene and Tropical Medicine, Universidade Nova de Lisboa, Lisbon, Portugal. \\ ${ }^{4}$ Departamento de Medicina Veterinária Preventiva, Universidade Estadual de Londrina, \\ Londrina, PR, Brazil.
}

Submitted: February 2, 2014; Approved: August 7, 2014.

\begin{abstract}
This study describes the detection of Borrelia garinii and Borrelia burgdorferi sensu stricto (s.s.) in Brazilian individuals using PCR and DNA sequencing. Our results suggest that these species are emerging pathogens in this country, and additional studies are necessary to determine the epidemiological characteristics of this disease in Brazil.
\end{abstract}

Key words: Brazil, human, lyme borreliosis, PCR, sequencing.

Lyme borreliosis (LB) is a tick-borne disease caused by genospecies of the Borrelia burgdorferi sensu lato (s.l.) complex (Steere, 1997). The genospecies causing LB vary according to the geographic region: $B$. andersonii, is mainly found in North America, B. afzelli and B. garinii in Europe, B. japonica in Japan, and B. burgdorferi sensu stricto (s.s.) has been detected on several continents (Qiu et al., 2008; Rudenko et al., 2011). Migratory birds cause the dissemination of Borrelia spp. between continents, and the establishment and maintenance of these spirochetes in a new environment depends on the presence of their reservoir hosts (tick species) and host-vector interactions (Hasle, 2013; Norte et al., 2013).

In Europe and North America, B. burgdorferi genospecies causing LB are mainly transmitted by the tick Ixodes ricinus (Steere, 1997; Qiu et al., 2008; Rudenko et al., 2011). In contrast, in Brazil, some studies have indicated the presence of these spirochetes in ticks from the Amblyomma, Rhipicephalus and Dermacentor genera, demonstrating the need for further studies to determine the vectors able to transmit LB in this country (Yoshinari et al., 2010; Gonçalves et al., 2013; Montovani et al., 2013).
In Brazil, this disease, which is known as Brazilian lyme-like disease or Baggio-Yoshinari syndrome, has been poorly studied (Yoshinari et al., 2010). Therefore, its epidemiology and most prevalent genospecies are not well defined (Dantas-Torres, 2008; Steps et al., 2009). Cases of this disease have been detected in humans and animals by serologic methods and/or by clinical symptoms in the northern (Amazonas and Tocantins States) (Abel et al., 2000; Carranza-Tamayo et al., 2012), midwestern (Mato Grosso do Sul State) (Costa et al., 2002; Naka et al., 2008), southeastern (Espírito Santo, Rio de Janeiro and São Paulo States) (Azulay et al., 1991; Passos et al., 2009; Yoshinari et al., 2003, 2010) and southern (Paraná State) (Gonçalves et al., 2013a, 2013b) regions of Brazil. Most of the cases affecting humans have been detected in inhabitants of rural areas, where the incidence of this zoonosis is high due to the close proximity of humans to the animal population, which are often parasitized by ticks.

Despite these findings, studies have reported negative serology in most of the individuals showing clinical signs of this disease and have failed to define its etiologic agent (Yoshinari et al., 2010). Studies involving this pathogen in Brazil have mainly assessed serology; thus, the aim of this

Send correspondence to D.D. Gonçalves. Programa de Pós-Gradução em Ciência Animal, Universidade Estadual de Londrina, Londrina, PR, Brazil / Medicina Veterinária Preventiva, Universidade Paranaense, Umuarama, PR, Brazil. E-mail: danieladib@unipar.br. 
study was to use molecular methods to determine the particular species of the B. burgdorferi s.l. complex that are present in humans in a small rural area in the northern region of Parana State, Brazil.

From February to November 2007, blood samples were collected voluntarily from 207 asymptomatic humans between 15 and 72 years of age living on 63 small rural properties in the northern region of Parana State. These residents also worked on family farms with animals.

After collection, the blood samples were forwarded to the Leptospirosis Laboratory of Preventive Veterinary Medicine Department at Universidade Estadual de Londrina (UEL) to obtain serum samples. Each sample was kept in a sterile container and stored at $-20^{\circ} \mathrm{C}$ until its use in the molecular tests, which were performed at the Laboratory of Leptospirosis and Lyme Borreliosis, Medical Microbiology Unit, Institute of Hygiene and Tropical Medicine (IHMT), Universidade Nova de Lisboa (UNL), Portugal.

DNA from the serum samples and the $B$. garinii culture (strain $\mathrm{PBi}$ ), which contained approximately $2 \times 10^{7}$ cells $/ \mathrm{mL}$ (used as a positive control), was extracted using the Puregene ${ }^{\mathrm{TM}}$ Gentra Cell \& Tissue Kit (Qiagen, Valencia, CA, USA) according to the manufacturers protocol. The extracted DNA was stored at $-20^{\circ} \mathrm{C}$ until further use.

The detection of the B. burgdorferi s.l. complex genospecies was performed by nested PCR targeting the $5 \mathrm{~S}(r r f)-23 \mathrm{~S}(r r l)$ intergenic spacer region, as previously described (Schwartz et al., 1992; Postic et al., 1994; Chao et al., 2011). Amplicons of 226-266 bp, depending on the strain of Borrelia spp., were purified, and both strands were directly sequenced by the Macrogen Sequencing Service, Inc. (Seoul, Korea). The primers used for DNA amplification were also used for sequencing. The results obtained were compared with existing Borrelia genospecies sequences in the GenBank database using the BLAST sequence analysis tool (http://blast.ncbi.nlm.nih.gov/Blast.cgi).

An epidemiological survey was also conducted using a structured questionnaire, in which the participants answered questions regarding risk factors related to the disease, including education level, the presence of domestic animals (dogs, cats and others), wild animals and rodents at the rural property, the presence of ticks attached to the body and the observation of ticks inside homes (Gonçalves et al., 2013).

The data obtained from the epidemiological survey were statistically analyzed using Yates or Fisher's exact test with a chi-square $\left(\chi^{2}\right)$ correction. The tabulations of the epidemiological data and analyses were performed using the EpiInfo statistical program version 6.04 (CDC) at a 5\% significance level. As an association measure, odds ratios (ORs) were calculated with confidence intervals of $95 \%$ (Dean et al., 1994).
Of the 207 human serum samples analyzed, two $(0.96 \%)$ showed positive nested-PCR results for the $B$. burgdorferi s.l. complex with amplicon sizes of $\sim 230 \mathrm{bp}$. The BLAST analysis showed high sequence similarity $(100 \%)$ with two different Borrelia genospecies. The nucleotide sequences obtained have been submitted to the GenBank database under the accession numbers KF790698 and KF790699. One strain (J-70) was identified as $B$. garinii, and the other strain (J-96) was identified as Borrelia burgdorferi s.s. (Figure 1A and 1B). Both samples were identified in males (15 and 72 years old, respectively) who worked with different animal species and performed various functions, such as assisting with births and slaughtering and castrating cattle. The analysis of the variables associated with the presence of Borrelia burgdorferi s.l. DNA is shown in Table 1.

The two nested PCR-positive serum samples for $B$. burgdorferi s.l. in this study have also been detected by indirect immunofluorescence assay (IFA) and western blot (WB) in a previously published study (Gonçalves et al., 2013a).

Brazilian lyme-Like disease, or Baggio-Yoshinari syndrome, was first reported in Brazil in 1992, but the causative agent of Borrelia infection has not been isolated or identified to date (Yoshinari et al., 2003, 2010). Many aspects of the disease, such as the symptoms and frequency of recurrence after treatment, appear to differ in Brazilian individuals compared with those inhabiting the northern hemisphere (Yoshinari et al., 2010). Moreover, Amblyomma cajennense and Rhipicephalus microplus ticks are believed to be involved in the transmission cycle of $B$. burgdorferi s.l. (Barros-Battesti et al., 2000; Yoshinari et al., 2003; Yparraguirre et al., 2007).

Researchers from different countries have detected $B$. burgdorferi s.l. DNA in ticks of the Dermacentor (Gonçalves et al., 2013b; Lledó et al., 2014), Ixodes (Leyedet et al., 2014; Morshed et al., 2006; Hjgaard et al., 2014; Dingler et al., 2014; Prusinki et al., 2014; Masuzawa et al., 2014; Barbieri et al., 2013) and Rhipicephalus (Maia et al., 2014; Niu et al., 2014) genera, which parasitize humans and different animal species. These studies have contributed to the understanding of borreliosis epidemiology, as they have indicated the main vectors involved in the transmission of this disease according to the region studied.

The presence of Borrelia burgdorferi s.l. was detected in Brazilian individuals by serological and molecular tests. Different researchers have demonstrated the presence of antibodies against $B$. burgdorferi s.s. and $B$. garinii by WB and/or ELISA tests in symptomatic and asymptomatic humans with histories of contact with ticks in Brazil (Costa et al., 2002; Naka et al., 2008; Gonçalves et al., 2013a).

A recent study in Brazil detected the flgE gene from B. burgdorferi by PCR and DNA sequencing in three peripheral blood samples collected from humans with clinical symptoms of borreliosis and histories of tick exposure 


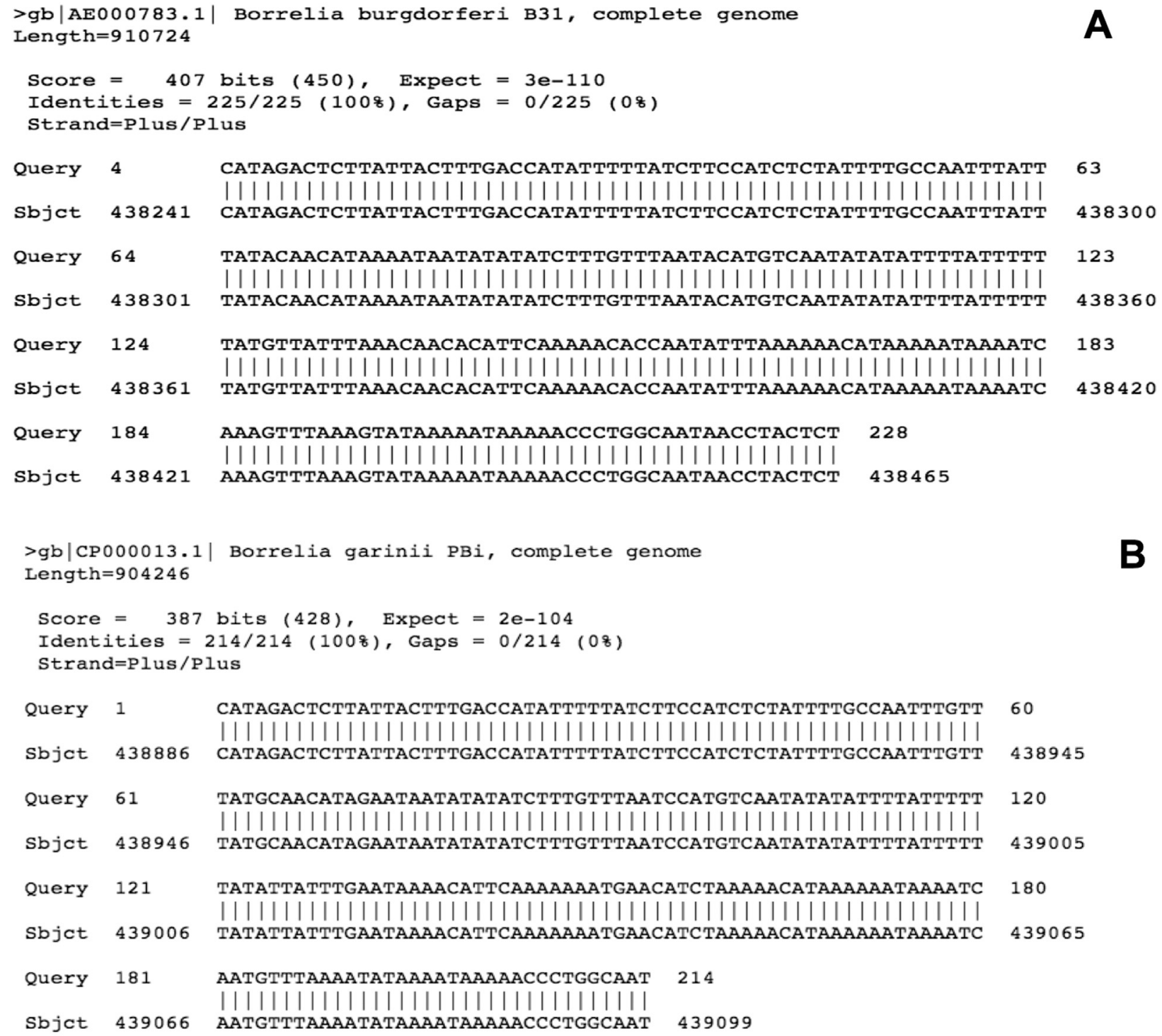

Figure 1 - BLAST sequence analysis. (A) Alignment comparison of sequences generated from serum sample J-96 with the $5 \mathrm{~s}(\mathrm{rrf})-23 \mathrm{~s}$ (rrl) intergenic spacer region of Borrelia burgdorferi B31 strain (AE000783.1); (B) Alignment comparison of sequences generated from serum sample J-70 with the 5S $(r r f)-23 \mathrm{~S}(r r l)$ intergenic spacer region of Borrelia garinii (Pbi strain) (CP000013.1).

Table 1 - Variables associated with the presence of DNA Borrelia burgdorferi s.1. in serum samples from 207 residents of the rural area of Jataizinho (PR), 2007.

\begin{tabular}{|c|c|c|c|}
\hline Disease variables & Positive DNA total (\%) & $\mathrm{p}$ value & OR CI ( $95 \%)$ \\
\hline \multicolumn{4}{|l|}{ Lyme Borreliosis } \\
\hline \multicolumn{4}{|c|}{ Ticks attached to the body } \\
\hline Yes & $02 / 16(12.50)$ & $0.0056^{*}$ & \\
\hline No & 00/191 (0.00) & & \\
\hline \multicolumn{4}{|c|}{ Presence of ticks inside of house } \\
\hline Yes & $02 / 27(7.40)$ & $0.0164 *$ & \\
\hline No & $00 / 180(0.00)$ & & \\
\hline
\end{tabular}

$\mathrm{p}=$ probability; * Fisher's exact test; OR = Odds ratio; $\mathrm{CI}=$ Confidence interval (Gonçalves et al., 2013). 
(Mantovani et al., 2012). Gonçalves et al. (2013b) also detected the presence of these bacteria in Brazil using PCR and DNA sequencing, indicating that the detected DNA sequences in two ticks of the Dermacentor nitens species shared $99.99 \%$ homology with the B. burgdorferi sensu stricto (s.s.) strain B31. Despite these findings, further studies are necessary to delineate the presence of this pathogen in Brazil.

In the present study, B. garinii and B. burgdorferi s.s. were detected by molecular methods for the first time in residents of rural areas, who were directly or indirectly exposed to wild and/or domestic animals and ticks in the northern region of Parana State, confirming the presence of these genospecies in Brazil. The variables studied, such as the presence of ticks inside homes $(p=0.0164)$ and the presence of ticks attached to the body $(p=0.0056)$, were significant when associated with the B. burgdorferi s.l. DNA findings. These data are in accordance with other studies, which have also associated tick exposure with illness in humans by serological techniques (Yoshinari et al., 2003, 2007; Mantovani et al., 2012; Gonçalves et al., 2013a).

However, the low frequency of Borrelia genospecies observed can be justified if these species are emerging pathogens in the country due to the dissemination of $B$. burgdorferi s.l. by migratory birds, and this hypothesis should not be discarded (Yoshinari et al., 2010; Hasle, 2013).

Studies of the Brazilian lyme-Like disease, or Baggio-Yoshinari syndrome, have revealed differences in epidemiological, clinical and laboratorial characteristics compared with those reported in affected individuals in the northern hemisphere, suggesting the existence of differing etiological agents in the two locations (Yoshinari et al., 2010). In Brazil, despite the wide geographical distribution of both invertebrate and vertebrate hosts for Borrelia spp., there are few descriptions of these spirochetes. Thus, further serological and molecular studies are needed in humans, different species of domestic and wild animals, and ticks, in particular, to better understand the epidemiology of Borrelia spp.

\section{Ethics Committee}

This research was approved by the Committee of Ethics in Research involving Humans (CEP) from the State University of Londrina (UEL) (No. 319/06).

\section{Acknowledgments}

We would like to acknowledge CAPES (Coordenação de Aperfeiçoamento de Pessoal de Nível Superior), the technical support of the Laboratory of Leptospirosis and Lyme Borreliosis, Medical Microbiology Unit, Institute of Hygiene and Tropical Medicine (IHMT) from the Univer- sidade Nova de Lisboa (UNL), Portugal, and Universidade Paranaense (UNIPAR) for the financial support.

\section{References}

Abel IS, Marzagao G, Yoshinari NH et al. (2000) Borrelia-like spirochetes recovered from ticks and small mammals collected in the Atlantic Forest Reserve, Cotia county, State of São Paulo, Brazil. Mem Inst Oswaldo Cruz 95:621-624.

Azulay RD, Azulay-Abulafia L, Sodre CT et al. (1991) Lyme disease in Rio de Janeiro, Brazil. Int J Dermatol 30:569-571.

Barbieri AM, Venzal JM, Marcili A et al. (2013) Borrelia burgdorferi sensu lato infecting ticks of the Ixodes ricinus complex in Uruguay: first report for the Southern Hemisphere. Vector Borne Zoonotic Dis 13:147-53.

Barros-Battesti DM, Yoshinari NH, Bonoldi VL et al. (2000) Parasitism by Ixodes didelphidis and I. loricatus (Acari: Ixodidae) on small wild mammals from an Atlatic Forest in the State of Sao Paulo, Brazil. J Med Entomol 37:820-827.

Carranza-Tamayo CO, Costa JN, Bastos WM (2012) Lyme disease in the state of Tocantins, Brazil: report of the first cases. Braz. J Infect Dis 16:586-589.

Chao LL, Chen YJ, Shih CM (2011) First isolation and molecular identification of Borrelia burgdorferi sensu stricto and Borrelia afzelii from skin biopsies of patients in Taiwan. Int J Infect Dis 15:182-187.

Costa IP, Bonoldi VL, Yoshinari NH (2002) Search for Borrelia sp. in ticks collected from potential reservoirs in an urban forest reserve in the State of Mato Grosso do Sul, Brazil: a short report. Mem Inst Oswaldo Cruz 97:631-635.

Dantas-Torres F (2008) Canine vector-borne diseases in Brazil. Parasites \& Vectors 1:25.

Dean A, Dean J, Coulombier D et al. (1994) Epi info. A word processing database and statistics program for epidemiology on microcomputers [computer program]. Version 6.

Dingler RJ, Wright SA, Donohue AM et al. (2014) Surveillance for Ixodes pacificus and the tick-borne pathogens Anaplasma phagocytophilum and Borrelia burgdorferi in birds from California's Inner Coast Range. Ticks Tick Borne Dis. pii: S1877-959X(14)00047-8. doi: 10.1016/j.ttbdis.2014.02.002. [Epub ahead of print].

Gonçalves DD, Benitez A, Lopes-Mori FM et al. (2013a) Zoonoses in humans from small rural properties in Jataizinho, Parana, Brazil. Braz J Microbiol 44:125-131.

Gonçalves DD, Carreira T, Nunes M et al. (2013b) First record of Borrelia burgdorferi B31 strain in Dermacentor nitens ticks in the northern region of Parana (Brazil). Braz J Microbiol 44:883-887.

Hasle G (2013) Transport of ixodid ticks and tick-borne pathogens by migratory birds. Front Cell Infect Microbiol 3:48.

Hojgaard A, Lukacik G, Piesman J (2014) Detection of Borrelia burgdorferi, Anaplasma phagocytophilum and Babesia microti, with two different multiplex PCR assays. Ticks Tick Borne Dis 5:349-351.

Leydet BF Jr, Liang FT (2014) Detection of Lyme Borrelia in questing Ixodes scapularis (Acari: Ixodidae) and small mammals in Louisiana. J Med Entomol 51:278-282.

Lledó L, Gegúndez MI, Giménez-Pardo C et al. (2014) A seventeen-year epidemiological surveillance study of Borrelia burgdorferi infections in two provinces of northern Spain. Int J Environ Res Public Health 11:1661-1672. 
Maia C, Ferreira A, Nunes M et al. (2014) Molecular detection of bacterial and parasitic pathogens in hard ticks from Portugal. Ticks Tick Borne Dis pii: S1877-959X(14)00043-0. doi: 10.1016/j.ttbdis.2014.01.009 [Epub ahead of print].

Mantovani E, Marangoni RG, Gauditano G et al. (2012) Amplification of the $f \lg E$ gene provides evidence for the existence of a Brazilian borreliosis. Rev Inst Med Trop S Paulo 54:153158.

Masuzawa T, Masuda S, Fukui T et al. (2014) PCR detection of Anaplasma phagocytophilum and Borrelia burgdorferi in Ixodes persulcatus ticks in Mongolia. Jpn J Infect Dis 67:47-49.

Morshed MG, Scott JD, Fernando K et al. (2006) Distribution and characterization of Borrelia burgdorferi isolates from Ixodes scapularis and presence in mammalian hosts in Ontario, Canada. J Med Entomol 43:762-773.

Naka EN, Costa IP, Arão CAB et al. (2008) Detection of antiBorrelia and anti-Babesia antibodies in the serum of children with clinical manifestations and compatible epidemiology with Lyme-Like disease in the State of Mato Grosso do Sul. Rev Bras Reumat 48:74-85.

Niu Q, Guan G, Yang J et al. (2011) Detection and differentiation of Borrelia burgdorferi sensu lato in ticks collected from sheep and cattle in China. BMC Vet Res 7:17.

Norte AC, Lobato DN, Braga EM et al. (2013) Do ticks and Borrelia burgdorferi s.l. constitute a burden to birds? Parasitol Res 112:1903-1912.

Passos SD, Gazeta RE, Latorre MR et al. (2009) Epidemiological characteristics of Lyme-like disease in children. Rev Assoc Med Bras 55:139-144.

Postic D, Assous MV, Grimont PA et al. (1994) Diversity of Borrelia burgdorferi sensu lato evidenced by restriction fragment length polymorphism of $\operatorname{rrf}(5 S)$ - $\operatorname{rrl}(23 S)$ intergenic spacer amplions. Int J Syst Bacteriol 44:743-752.

Prusinski MA, Kokas JE, Hukey KT et al. (2014) Prevalence of Borrelia burgdorferi (Spirochaetales: Spirochaetaceae),
Anaplasma phagocytophilum (Rickettsiales: Anaplasmataceae), and Babesia microti (Piroplasmida: Babesiidae) in Ixodes scapularis (Acari: Ixodidae) collected from recreational lands in the Hudson Valley Region, New York State. J Med Entomol 51:226-236.

Qiu WG, Bruno JF, McCaig WD et al. (2008) Wide distribution of a high-virulence Borrelia burgdorferi clone in Europe and North America. Emerg Infect Dis 14:1097-1104.

Rudenko N, Golovchenko M, Grubhoffer L et al. (2011) Updates on Borrelia burgdorferi sensu lato complex with respect to public health. Ticks Tick Borne Dis 2:123-128.

Schwartz JJ, Gazumyan A, Schwartz I (1992) rRNA gene organization in the Lyme disease spirochete, Borrelia burgdorferi. J Bacteriol 174:3757-3765.

Steere AC (1997) Diagnosis and treatment of Lyme arthritis. Med Clin North America 81:179-194.

Yoshinari N, Spolidorio M, Bonoldi VL et al. (2007) Lyme disease like syndrome associated lymphocytoma: first case report in Brazil. Clinics 62:525-526.

Yoshinari NH, Abrao MG, Bonoldi VL et al. (2003) Coexistence of antibodies to tick-borne agents of babesiosis and Lyme borreliosis in patients from Cotia county, State of Sao Paulo, Brazil. Mem Inst Oswaldo Cruz 98:311-318.

Yoshinari NH, Mantovani E, Bonoldi VLN et al. (2010) Brazilian lyme-like disease or Baggio-Yoshinari syndrome: exotic and emerging Brazilian tick-borne zoonosis. Rev Assoc Med Bras 56:363-369.

Yparraguirre LA, Machado-Ferreira E, Ullmann AJ et al. (2007) A hard tick relapsing fever group spirochete in a Brazilian Rhipicephalus (Boophilus) microplus. Vector Borne Zoonotic Dis 7:717-721.

Associate Editor: Agnes Marie Sá Figueiredo

All the content of the journal, except where otherwise noted, is licensed under a Creative Commons License CC BY-NC. 